Disputatio's Symposium on Berit Brogaard's Transient Truths

Oxford University Press, 2012

\title{
Temporalism and Composite Tense Operators
}

\author{
Dan Zeman \\ Universitat Pompeu Fabra \\ BIBLID [0873-626X (2013) 37; pp. 323-328]
}

Berit Brogaard's book, Transient Truths. An Essay in the Metaphysics of Propositions is the most complete and thorough defence of temporalism to date. Temporalism, as she understands it, is the view that the objects of our attitudes such as belief, fear, desire and so on, as well as the entities expressed by some of our utterances, are temporal propositions - that is, contents that change their truth value over time. The opposite view, considered the orthodox view nowadays, is the view that such contents are eternal propositions - that is, contents that have their truth value eternally - hence, eternalism. In her book, Brogaard investigates all the major arguments against and in favour of temporalism, offering a couple of new ones in its favour along the way. One of the nice features of the book is that the interconnections between the various areas of philosophical inquiry in which temporalism is a competitor clearly come to the fore, while the contribution made by the view in each area is thoroughly investigated are carefully argued for. Thus, temporalism is put forward in connection to the theory of belief possession and retention (Chapter 2), to that of communication and of disagreement (Chapter 3), to the syntactic and semantic theory of tenses and temporal expressions (Chapters 4 to 6 ) and to the metaphysics of time (Chapters 7 and 8).

Given the book's wide range, there are many interesting and important issues to pick up. In this short note, I will focus only on the issue of the linguistic representation of tenses and temporal expressions, a field in which temporalism has been one of the traditional answers. This traditional answer, however, has been called into question in recent years, and a lively debate has issued. It is this debate that I want to focus on, and discuss Borgaard's contribution 
to it. I will thus start with presenting the challenges she attempts to answer to, sketch her solution and then raise some worries about her proposal.

In chapter 4, Brogaard enters the debate between temporalism and eternalism in the context of providing the best syntactic and semantic theory of tenses, and purports to offer an answer to the often rehearsed arguments against temporalism summarized in King 2003, 2007. Those arguments show that the operator treatment to tenses and temporal expressions temporalists favour is, if not strictly speaking incorrect, more cumbersome, ad-hoc and significantly departing from the surface structure of English (King 2007: chapter 6). What King points out is that the operator treatment of tenses has at least prima facie problems with linguistic phenomena such as the interaction between tenses and temporal adverbials ('Yesterday, John turned off the stove'), temporal anaphora ('Sheila had a party last Friday, and Sam got drunk') and the so-called 'Kamp/Vlach sentences' ('One day, all persons alive now will be dead') — among others. Given that a quantificational treatment of tenses yields simpler results in dealing with these phenomena, and the (sociological) fact that the majority of linguists have given up the Priorian framework and have adopted a quantificational or referential approach to tenses instead — King argues — , temporalism should be abandoned. ${ }^{1}$

In response, Brogaard proposes a new view of tenses and temporal expressions that is supposed to vindicate temporalism and which also accounts for the problematic phenomena mentioned by King. First, Brogaard distinguishes between two kinds of tense operators: basic ones, such as 'It was the case that' and 'It will be the case that', and composite ones, which result from the combination of basic tense operators with a variety of temporal adverbial phrases. Within the last we find indexical frame adverbials ('this morning'), non-indexical frame adverbials ('in June 2030 (CST)'), durative adverbial phrases ('for two weeks'), mixed durative and frame adverbials ('for the last two hours'), adverbial subordinate clauses ('before I

\footnotetext{
${ }^{1}$ How strong King's actual claims are, and whether they licence the abandonment of the Priorean framework, is a matter of dispute. While it is true that most of those opposed to temporalism have taken King to offer a clear refutation of the view, not everybody is convinced — see Recanati 2007 and Marti \& Zeman 2010, for example.
} 
was born') and adverbial phrases of number and frequency ('never'). Although not all such adverbial phrases behave similarly in combining with tenses (for example, some of them 'scope out', while others don't), the combination of most of them with basic tense operators results in composite tense operators that are interpreted as circumstance-shifting sentential operators. Second, and this is the core claim of the view, the problematic phenomena mentioned by King can be accounted for by appeal to composite tense operators. In Chapter 4 Brogaard shows how this view accommodates the phenomena mentioned above, while in Chapter 5 she applies it to yet other troublesome phenomena, such as sequence of tense, noun denotations, 'Partee sentences' etc. To give just one example of how the proposal works, the problematic sentence 'Yesterday, John turned off the stove' will be represented using the composite tense operator 'It was the case yesterday that', which takes as input the tenseless content 'John turn off the stove' and shifts the evaluation time of the embedded content to a past time that belongs to the class of times picked out by the adverb 'yesterday', thus yielding the required truth conditions.

Brogaard's proposal is original and, if successful, would indeed offer an elegant treatment of the phenomena mentioned by King that is temporalist in nature. I have, however, a few worries about the proposal, the arguments for it and the general argumentative strategy of the book. The first worry concerns the syntactic evidence that is adduced in favour of the view that Brogaard presents, namely that tenses are circumstance-shifting sentential operators. To put it bluntly, I'm worried that there is not much positive evidence that is brought to support that view. The point is not that Brogaard doesn't appeal to empirical data — in fact, she considers the very same linguistic phenomena that King appeals to. But what she offers is a reinterpretation of the phenomena, rather than positive syntactic arguments for it. Is this, by itself, enough to counter King's allegations that temporalism cannot account for certain linguistic phenomena? Possibly so. But some true supporters of temporalism would want more than that: they would want positive, decisive arguments for the view that tenses are to be interpreted as circumstance-shifting sentential operators, rather than, say, quantifiers over temporal variables verbs come endowed with. The problem seems to me to be 
serious, given that Brogaard follows King in holding that

'the claim that tenses are operators that shift features of the index of evaluation is an empirical claim about natural language. It is a claim to the effect that in the best syntax and semantics for natural language, tenses will be treated syntactically and semantically as such operators.' (King 2003: 215, quoted in Brogaard 2012: 81).

As far as I can tell, no positive evidence that the view proposed is 'the best syntax for natural language' has been given.

A second, related worry concerns composite tense operators. As we have seen, Brogaard draws a distinction between basic tense operators and composite ones. A composite tense operator is the result of the syntactic combination between a basic tense operator and any of the temporal adverbial phrases mentioned above. Brogaard claims that the combination between such a phrase and a sentential operator is a novel, more complex sentential operator, and she is definitely right about that. But whether the composite tense operator is sentential depends entirely on the basic tense operators being sentential. However, if what I said above is right, no positive case that this is so has been made. One is thus tempted to ask: if there is no positive syntactic evidence for basic tense operators being sentential, what grounds do we have to claim that composite ones are sentential? What stops us from claiming, instead, that the combination of the basic tense operators with the various temporal adverbial phrases results in the creation of a complex adverbial phrase that might be interpreted not as a complex sentential operator, but, say, as a complex quantifier phrase? The point is not that composite tense operators won't solve the problems King and other have pressed against the temporalist; the point is that the account works only if it is presupposed that basic tense operators are sentential. But this, it seems to me, is what was at stake from the beginning; this is what temporalism requires and what its defenders were supposed to prove. Taking for granted that basic tense operators are sentential seems to put the cart before the horse, and prevents the temporalist to claim a clear victory over her competitors.

But perhaps Brogaard's forage into the syntax and semantics of tenses and temporal expressions is better seen as a defensive move against anti-temporalists such as King, rather than as purporting to offer positive arguments for the view. This opens up a more general 
issue related to the argumentative strategy Brogaard employs in her book. Usually, a viable operator treatment of tenses has been taken to give solid reasons for the postulation of time-neutral contents that is, reasons for temporalism. This line of reasoning has been captured by what came to be known as 'the operator argument', the most prominent proponent and defender of which being Kaplan 1989. The success of the argument has been, of course, denied. (Brogaard tackles and defends this argument in Chapter 6.) But what I want to point out it that the strategy considered above can also be reversed. Instead of arguing from syntactic and semantic considerations about tenses and temporal expressions to temporalism, one could instead argue from other kinds of considerations to temporalism, and then propose an operator treatment of tenses and temporal expressions as fitting best with temporalism. We can find an example of such a reversed strategy in Recanati 2007: in his opinion, temporalism is best defended by considerations having to do with language learning and the regimentation of complex expressions in a simple language (2007: part 2), while the operator treatment of tenses is adopted as a consequence. Now, the question that arises in connection to Brogaard's book is the following: which is the direction of argumentation she favours? If my remarks above are on the right track, it is doubtful that the first direction will be successful. On the contrary, even if I am right about the above, the second direction is still available to her - and with significant results too. Of course, that puts additional dialectical weight on her other arguments for temporalism given in the book (that from belief possession and retention given in Chapter 2, that from disagreement given in Chapter 3, etc.). But assuming that those arguments are successful, the result that tenses should be treated as circumstance-shifting sentential operators can easily be achieved. ${ }^{2}$

\footnotetext{
${ }^{2}$ This presupposes that the operator treatment to tenses is the only one compatible with temporalism. There are, however, other views of tenses that are compatible with temporalism. The 'mixed view' hinted at in Recanati 2007 and developed in Zeman (ms.) is one example. So, following the second direction of argumentation described above doesn't strictly speaking lead us directly to a sentential operator treatment of tenses. I will set aside such complications in this note.
} 
In sum, while I think there are weak points in Brogaard's arguments for an operator treatment of tenses and temporal expressions, the book as a whole contains many illuminating discussions of important issues pertaining to more than one area of philosophical inquiry. True, some of her positive proposals would benefit from a more developed treatment (such as, for example, the application of her proposal to the complicated linguistic phenomena dealt with in Chapter 5). This observation, however, is not a criticism of the book as such; it is, rather, an invitation to further develop the interesting points made in future work.

Dan Zeman

Universitat Pompeu Fabra Department of Translation and Language Sciences Roc Boronat 138, 6th floor, office 53610

08018 Barcelona dan.zeman@upf.edu

\section{References:}

Brogaard, B. 2012. Transient Truths. An Essay in the Metaphysics of Propositions. Oxford University Press.

Kaplan, D. 1989. Demonstratives. In Themes from Kaplan, ed. by J. Almog, J. Perry and H. Wettstein, 481-563. Oxford University Press.

King, J. 2003. Tense, Modality and Semantic Values. Philosophical Perspectives 17: $195-245$.

King, J. 2007. The Nature and Structure of Content. Oxford University Press.

Marti, G. and Zeman, D. 2010. Review of Jeffrey King, 'The Nature and Structure of Content', Oxford University Press, 2007. Mind 119 (475): 814-19.

Recanati, F. 2007. Perspectival Thought. A Plea for (Moderate) Relativism. Oxford University Press.

Zeman, D. (ms.) Temporalism in an Extensional Framework. Retrievable at http://institutnicod.academia.edu/DanZeman/Drafts. 